\title{
Gene Regulation through mRNA Expression
}

\author{
Haruko Inose*, Kotomi Mukai, Misa Ito, Seiji Masuda* \\ Division of Integrated Life Science, Graduate School of Biostudies, Kyoto University, Kyoto, Japan \\ Email: ${ }^{*}$ inose.haruko.24n@st.kyoto-u.ac.jp, ${ }^{*}$ masuda@kais.kyoto-u.ac.jp
}

Received 24 December 2014; accepted 27 February 2015; published 5 March 2015

Copyright (C) 2015 by authors and Scientific Research Publishing Inc.

This work is licensed under the Creative Commons Attribution International License (CC BY).

http://creativecommons.org/licenses/by/4.0/

(c) (i) Open Access

\begin{abstract}
In eukaryotes, gene expression is achieved by four steps: transcription, processing, nuclear export, and translation. Each step requires multiple factors, and frequently two or more pathways are used by a single gene, enabling strictly regulated gene expression. Importantly, eukaryotes, taking advantage of the separated structures of the nucleus and the cytoplasm, have evolved complex and organized mRNA processing mechanisms that permit sophisticated biological activity. The processes are much more complicated than those found in prokaryotes, in which transcription and translation occur linearly in time and place. Here, we review gene expression, focusing on mRNA processing in the nucleus and the gene regulatory systems found at each step. Combination of gene regulation shows the typical phenotype in each cell. Further understanding of the uncertain mechanisms will uncover the gene regulation through mRNA expression.
\end{abstract}

\section{Keywords}

Capping, Splicing, Polyadenylation, Export, Half Life

\section{Introduction}

Gene expression in eukaryotes is characterized by the spatially separated processes of transcription and translation. Despite having an identical genome, varying levels of gene expression within differing types of cells permit different biological activities in response to both the internal (developmental, cell cycle-related) and external environments. This provides the range of functions necessary for higher eukaryotes.

Gene regulation is found at each of the six steps of gene expression: 1) transcriptional regulation; 2) mRNA processing control; 3) mRNA transport and localization; 4) translational regulation; 5) protein activity; and (6) mRNA half-life. In the last two decades, it has been shown that mRNA metabolism plays important roles in gene regulation.

In the first section, we provide an overview of gene expression, mostly in higher eukaryotes, focusing on

${ }^{*}$ Corresponding authors. 
mRNA processing: capping, splicing, polyadenylation, and mRNA export. In the second section, we summarize gene regulation, focusing on mRNA processing control, mRNA transport, and mRNA half-life.

\section{Gene Expression in Eukaryotes}

\subsection{Capping}

Nascent mRNA, when about 20 bases have been synthesized by RNA polymerase II (polII), is first modified by "capping" [1]. Capping is a hallmark of transcription initiation that functions to protect mRNA from degradation by 5'-3' exonuclease activity (Figure 1). Three enzymatic reactions are required for capping: hydrolysis of the 5' terminal phosphate by RNA triphosphatase, addition of a guanine residue to the trimmed diphosphate terminus by RNA guanyltransferase, and methylation of the guanine residue by RNA methyltransferase. After capping, nascent mRNA contains an N7-guanosine cap “m7GpppN” at its 5' terminus via an unusual 5'-5' phosphodiester linkage. The cap structure is required not only for mRNA nuclear export but also for translation: the capbinding complex (CBC) formed by CBP80 and CBP20 binds to the cap in the nucleus, whereas eukaryotic elongation factor (eIF) $4 \mathrm{E}$ binds to the cap in the cytoplasm.

\subsection{Splicing}

In eukaryotes, most genes consist of protein-coding regions called exons, which are interspersed by untranslated regions called introns. The removal of introns by splicing is required to generate contiguous coding regions in the nucleus. The exact position of the 5'splice site (at the 5' terminus of the intron) and the 3' splice site (at the 3' terminus of the intron) is determined by the RNA sequence as well as by trans-acting factors and uridine-rich

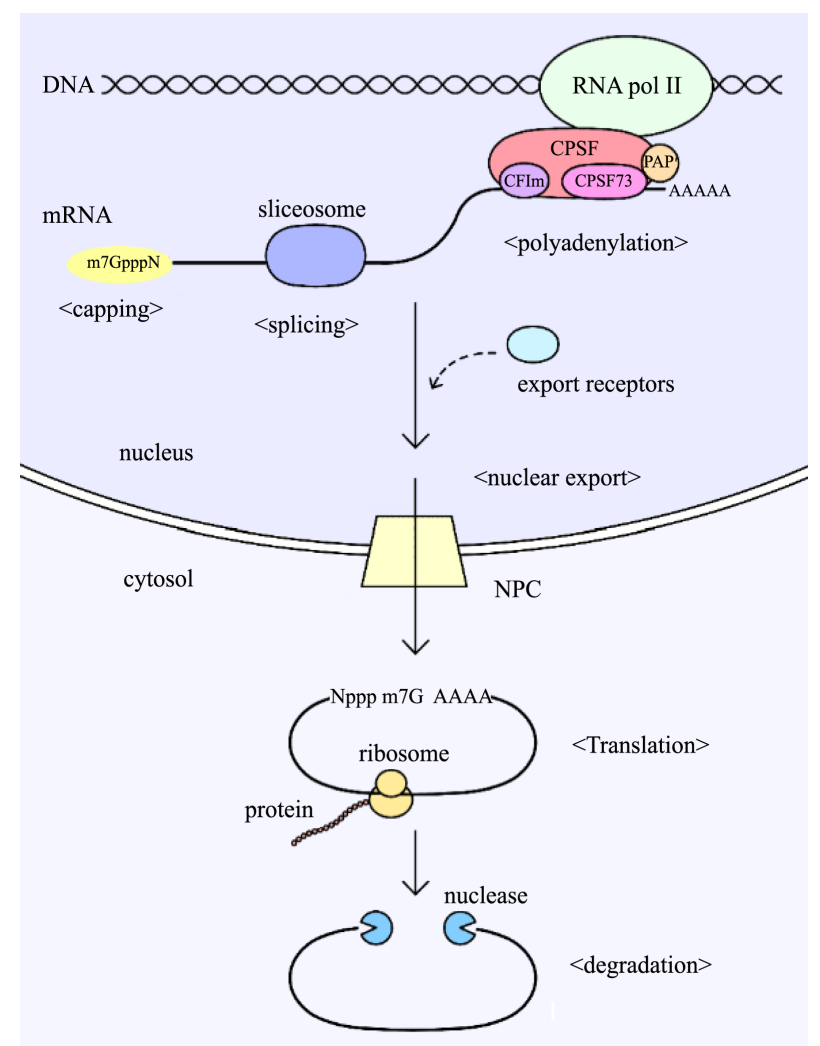

Figure 1. mRNA biogenesis. Pol II transcribes the protein coding genes in the nucleus. Transcribed pre-mRNA undergoes the various processing steps, capping, splicing and polyadenylation. The properly-processed mRNA is exported from the nucleus to the cytoplasm. In the cytoplasm, mRNA serves as a template for protein synthesis. 
small nuclear ribonucleoprotein particles (U snRNPs). Typically, the 5' splice site has a consensus "GU” dinucleotide, and the 3' splice site has "AG". In addition, a branch point site and polypyrimidine (Py) tract are also required. The branch point site is an adenine residue that attacks the 5' splice site and dissociates the exon from the intron; it is usually found several tens of bases upstream of the 3' splice site. Py is a sequence rich in adenine and uracil found between the branch point site and the 3' splice site.

Splicing is an energy-consuming process that is catalyzed by the spliceosome [2] [3]. The spliceosome is a large complex of about 150 proteins and five U snRNAs. Intriguingly, uridine-rich small nuclear ribonucleic acids (U snRNAs), which are small RNAs with complementarity to pre-mRNA, form the active site of the spliceosome. As indicated in Figure 2, the 5' splice site is first recognized by U1 snRNP via base-pairing. However, the Py and 3' splice site are recognized by U2AF, which results in the recruitment of branch point-binding protein (BBP). BBP is then replaced by U2 snRNP, which makes the branch point site protrude from the RNA chain. Next, U4, U5, and U6 snRNPs undergo complex interactions with each other. U1 snRNP then dissociates from the RNA, to be replaced by U6 snRNP. After U4 snRNP dissociates, U2 snRNP and U6 snRNP bind each other via base-pairing. Importantly, U2 snRNP positions itself at the branch point site while U6 snRNP is positioned at the 5' splice site at this point, thus enclosing 5' splice site and branch point site in proximal region. As a result, the branch point site attacks the 5' splice site phosphate and the intron is spliced out. Finally, the 3' terminus of the upstream exon attacks the downstream exon 5' terminus that is dissociated from the 3' splice site, connecting them together. This complex procedure for splicing, in which the components of the spliceosome are sequentially replaced to ultimately generate a catalytically active site, enables cells to avoid aberrant splicing.

\subsection{Polyadenylation}

Most mRNA has a poly-A tail at its 3' terminus, which is not encoded by the genome. When RNA polII reaches the end of a gene, two polyadenylation factors, cleavage and polyadenylation specificity factor (CPSF) and cleavage stimulation factor (CstF), are recruited onto its C-terminal domain (CTD). CPSF, which recognizes the

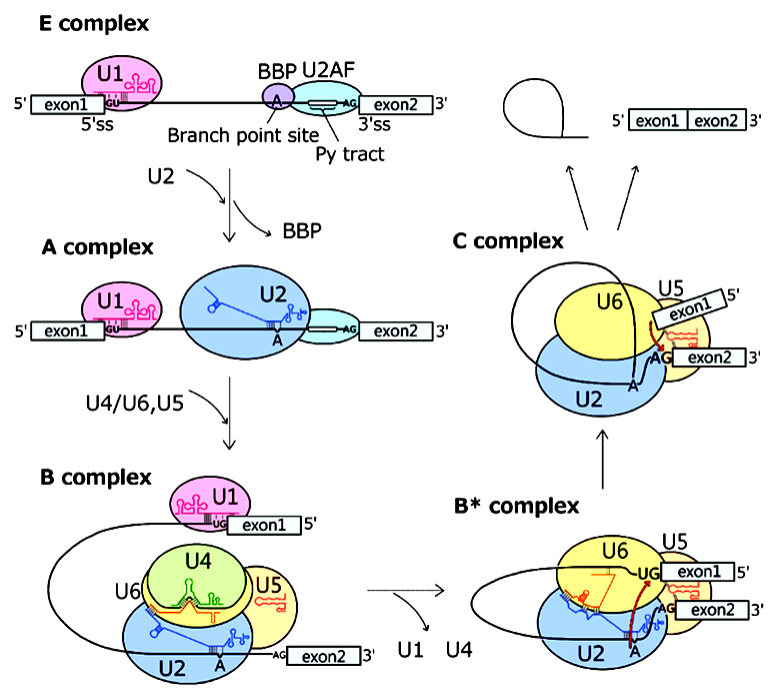

Figure 2. Dynamics of mRNA splicing. Formation of spliceosome is a stepwise event, starting from E complex followed by forming A, B, B' and C complexes in this order. In E complex, U1 snRNP is associated at 5' splice site, and Branch point binding protein (BBP) and U2AF are associated at brunch site and 3' splice site, respectively. In A complex, U2 snRNP is recruited to 3' splice site. In B complex, U4/U6 and U5 snRNPs are recruited to U2 snRNP. In B* complex, $\mathrm{U} 1$ and $\mathrm{U} 4$ snRNPs are dissociated from pre-mRNA, and U2 and U6 snRNP form duplex to enable 5' and 3' splice sites in a proximal region. In $\mathrm{C}$ complex, splicing occurs in two-step reaction and intron is removed from mRNA. 
poly-A signal "AAUAAA", and CstF, which recognizes a GU-rich element downstream of "AAUAAA", are translocated onto the mRNA when RNA polII transcribes these sequences. The cleavage factors I and II cleave nascent mRNA with the support of CPSF and CstF, followed by the recruitment of poly-A polymerase (PAP) to the end of the transcript. PAP then adds approximately 200 adenines to the 3' terminus of the nascent mRNA [4].

The poly-A tail plays important roles in two phases. First, it is recognized by poly-A-binding protein (PABP) [5]. In the cytoplasm, PABP interacts with the 5' cap via interaction with eIF4G, a protein bound to eIF4E. Interaction between the poly-A tail and the 5' cap results in circularization of the mRNA, enabling efficient ribosomal cycling and translation. Second, PABP bound on the poly-A tail protects the mRNA from 3'-5' nuclease attack, extending its half-life. The poly-A tail is gradually shortened over time. When it becomes too short to bind PABP, the exosome recognizes and degrades mRNA in the 3' to 5' direction.

\subsection{Nuclear Export}

Macromolecules usually require receptors for their nuclear trafficking through the nuclear pore complex (NPC); this also applies to mRNA export. Two proteins, TAP (also called NXF1) and CRM1 (also called XPO1) have been identified as nuclear export receptors for different classes of mRNA export.

TAP is responsible for bulk mRNA export [6] [7]. This export pathway is highly coupled to splicing in humans. In contrast, Mex67, its homolog in Saccharomyces cerevisiae, is recruited onto primary transcripts because only approximately $5 \%$ of genes in this species contain introns [8] [9]. Intron-containing nascent transcripts are recognized and bound by the spliceosome via their introns, which results in the recruitment of TREX during splicing [10]-[13]. TREX ultimately recruits TAP - the recruitment of TAP to mRNA therefore depends on splicing. So, how does TAP export mRNA from the nucleus to the cytoplasm? TAP is known to bind the FGrepeat in nucleoporins, the major components of the NPC. This binding ability promotes mRNA export to the cytoplasm [14]-[17]. In addition, on the cytoplasmic side of the NPC, DBP5, a DEAD-box helicase connected to NPC fibrils, remodels mRNPs in concert with Gle1 and IP6 and releases mRNPs into the cytoplasm by dissociating several proteins including TAP [18]-[20]. It is considered that the TAP-mediated mRNA export pathway, by virtue of its splicing dependence, prevents the export of incompletely spliced mRNA.

However, several kinds of mRNA use CRM1 as their export receptor [21]. The CRM1-mediated export pathway seems to be independent of splicing. While TAP is recruited onto mRNAs via splicing in humans, CRM1 is recruited onto mRNAs via specific adapter proteins that bind to a cis-RNA element in the 3' untranslated region (UTR). Moreover, the CRM1-mediated pathway is different from the TAP-mediated pathway in the way it remodels the exported mRNPs at the cytoplasmic face of the NPC. When an mRNP is released into the cytoplasm, Ran plays a key role in the CRM1-mediated pathway (the equivalent of DBP5 in the TAP pathway) [22] [23]. Ran is a small GTPase that is present as Ran-GTP in the nucleus, where GTP exists at a high concentration by the catalytic activity of the chromatin-bound guanine nucleotide exchange factor RCC1 [24]. In contrast, Ran exists in a GDP-bound form in the cytoplasm, where GTP is hydrolyzed by the catalytic activity of the Ran GTPase-activating protein RanGAP. Ran works like a switch: CRM1 bound to Ran-GTP in the nucleus binds to the adapter protein with specific RNA elements including mRNA, while CRM1 dissociates from RanGDP in the cytoplasm to release the adapter protein.

\section{Gene Regulation}

\subsection{Gene Regulation via Capping}

Historically, it was considered that capping did not actively affect gene regulation because it was a universal process. However, this view has now been challenged. The complete cap structure is required for recognition by $\mathrm{CBC}$, and thus an accelerated capping reaction may enhance gene expression. Several mechanisms have been identified that enhance methylation, the final step in cap generation (Figure 3). In yeast, S-adenosylmethionine (SAM), which serves as a methyl donor in capping, and its related factors, have been shown to affect cap methylation. SAM synthase activates Abd1, a yeast RNA (guanine-7-) methyltransferase (RNMT) that catalyzes SAM to produce a methylated cap and S-adenosyl-L-homocystein (SAH) [25]. SAH, in turn, inhibits the activity of Abd1 until it is hydrolyzed by S-adenosyl-L-homocysteine hydrolase (SAHH) [26].

In humans, importin $\alpha$ has been identified as a binding partner of $\mathrm{CBC}$ that improves the efficiency of cap 
(a)

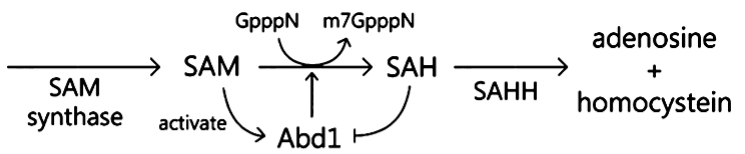

(b)

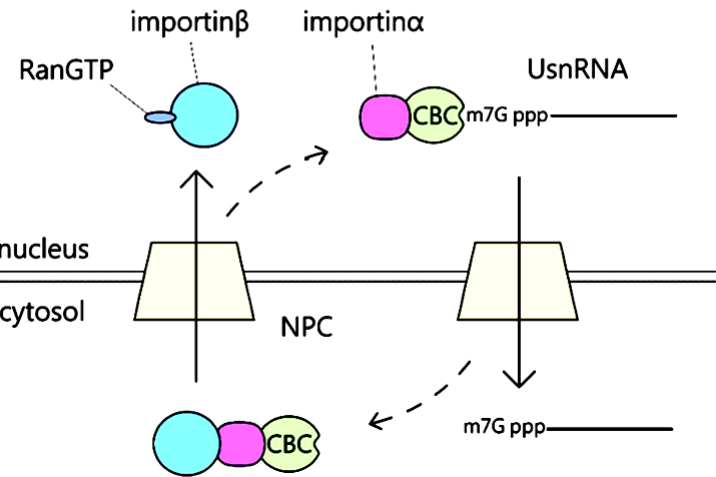

Figure 3. Regulation of cap methylation. (a) Feedback regulation of the cap methylation. Abd1 is activated by SAM followed by catalyzing cap methylation. SAH, by-product of cap methylation, inhibits Abd1; (b) Regulation of the cap methylation by importin $\alpha$ and $\beta$, and Ran-GTP.

methylation. In yeast, importin $\alpha$ is normally bound to CBC, which means that CBC in complex with importin $\alpha$, not CBC alone, recognizes capped U snRNA [27]. However, the binding of importin $\beta$ to importin $\alpha$ triggers the dissociation of the importin $\alpha$-CBC complex from capped U snRNA [27]-[29]. Thus, in the nucleus, where importin $\beta$ is bound to Ran-GTP, the importin $\alpha$-CBC complex binds to capped U snRNA, while in the cytoplasm, where importin $\beta$ is free from Ran, the importin $\alpha$-CBC complex dissociates from capped U snRNA. Importantly, the activity of Ran is known to be enhanced by growth factors, suggesting that external signals promote the formation of the importin $\alpha$-CBC-cap complex, resulting in the promotion of cap methylation [29].

m7GpppN is not the only nucleotide to be methylated in the capping reaction. The ribose adjacent to the cap, namely, the first transcribed ribose, and following riboses are often methylated to produce methylated-ribose 1 (cap1), cap2, and so on. Cap0, the GpppN that is added to the 5' terminus of mRNA, and cap1, are found in all human mRNA, while mcap2 is found in only half of human mRNA [30]. The observation that the 5' mRNA terminus can have different methylation levels implies the existence of something similar to the "histone code" to regulate gene expression. Cap4, a hypermethylated structure found in Trypanosoma brucei mRNA, supports this idea by the fact that the cap4 structure is required for maximum translation [31]. It is as yet unknown how a difference in methylation levels can affect gene expression, and similarly what determines the methylation levels, although recent studies have attempted to identify the consensus sequence for cap1 and cap2, and investigate the structure of hMTR1 and hMTR2, which are the human methylases for cap1 and cap2, respectively [32]-[34].

Emerging data have shown that decapping also functions as a gene regulatory step. DCP2 is a canonical decapping enzyme in humans [35] [36]. When the poly-A tail becomes too short to bind PABP, the circular formation between the 5' cap and the poly-A tail is no longer maintained, and DCP2 hydrolyzes the cap structure, resulting in rapid degradation of mRNA by Xrn1, a 5'-3' exonuclease that recognizes the 5' monophosphate terminus. Decapping is upregulated in conditions of environmental stress such as starvation or heat shock. Importantly, long non-coding (lnc) RNA, as well as mRNA, is a target of decapping by DCP2. Some lncRNAs repress the transcription of stress-inducible genes by forming an R-loop (DNA:RNA hybrid) with the corresponding genomic region. The reduction in the amount of relevant lncRNA is followed by increased expression of stressinducible genes. Thus, cells can modulate their metabolism by reducing canonical mRNA, meanwhile enabling the expression of stress-inducible genes.

In addition, a non-canonical decapping enzyme has also been identified, which is suggested to function in the capping quality control mechanism. In yeast, Rai1 (DOM3Z in humans) has been shown to degrade mRNA with a methylation-defective cap [37]. In Rai1-deficient yeast, the accumulation of mRNA with an aberrantly methy- 
lated cap can be observed under glucose or amino acid starvation, which indicates that Rai1 controls mRNA translation by degrading aberrantly capped mRNA.

\subsection{Alternative Splicing}

Most exons are constitutively spliced so as to be retained in the mature mRNA. Meanwhile, some exons are spliced in different patterns; this process is called "alternative splicing". Alternative splicing plays important roles in the versatility of proteins derived from a single gene in different cell types or developmental stages. When alternative splicing is disrupted, it impairs a wide range of developmental and physiological functions, often with pathological consequences. Here, we describe the classification and mechanisms of alternative splicing, although the details of the so-called "splicing code" remain to be understood.

The major forms of alternative splicing are categorized by five patterns [38]. They are: 1) exon skipping; 2) alternative 3' splice site usage; 3) alternative 5' splice site usage; 4) intron retention; and 5) mutually exclusive exons. Exon skipping is the most common form. Complicated patterns of splicing arising from combinations of two mechanisms are also observed.

Alternative splicing is typically controlled by cis-acting splicing regulatory elements (SRE), which can be observed in both exons and introns, and function as either splicing enhancers or silencers [39] [40]. Splice site selection is regulated by SREs and trans-acting splicing factors bound to SREs. According to their locations and activities, SREs are classified into four types: exonic splicing enhancers and intronic splicing enhancers (that stimulate splicing), and exonic splicing silencers and intronic splicing silencers (that inhibit splicing). Accessibility to splice sites or SREs is determined by the structures of the pre-mRNA and RNA-binding proteins [3] [41]. Serine/arginine-rich (SR) protein and heterogeneous nuclear ribonucleoprotein (hnRNP) are important trans-acting factors. SR protein promotes splicing when it is bound to exons, whereas it inhibits splicing when it is bound to introns [42] [43]. hnRNP also controls splicing positively and/or negatively according to the particular pre-mRNA it is associated with [43] [44].

SRSF1 (also celled SF2/ASF), a member of the SR family, affects the alternative splicing of various targets, including the proto-oncogene RON. SRSF1 promotes the skipping of RON exon 11, which results in cell motility and invasion [45]. SRSF1 promotes the expression of anti-apoptotic isoforms which cannot interact with proapoptotic factors or inhibit the action of pro-apoptotic factors such as MYC [46]. BIM belongs to the BCL2 family and promotes apoptosis by inhibiting anti-apoptotic BCL2 family members [47]. BIN1 interacts with MYC and promotes apoptosis. Overexpression of SRSF1 promotes the expression of two BIM isoforms, called $\gamma 1$ and $\gamma 2$, lacking exon 2 and 3, and BIN1 lacking exon 13 [46]. An increase in BIM $\gamma 1$, which lacks pro-apoptotic activity, and a decrease in exon 13-containing BIN1, which has lost its interaction with MYC, contribute to the SRSF1-induced phenotype. In short, SRSF1 regulates apoptosis by promoting the expression of BIN1 and BIM isoforms lacking pro-apoptotic activity.

hnRNP L, a member of the hnRNP family, regulates splicing in a position-dependent manner. hnRNP L was initially discovered as a splicing activator of the human eNOS. It binds to the CA-repeat region of the intron upstream of exon 13 [48]. However, two reports have shown that hnRNP L represses alternative splicing by competing with U2AF for intron binding close to the 3' splice site, as demonstrated for the TJP1 [49] [50]. Thus, hnRNP L represses the splicing of alternative exons when it is bound to intronic regions upstream of these exons, and activates splicing when it is bound to intronic regions downstream of alternative exons [51].

In the forskolin/protein kinase A pathway, hnRNP K binds to the KARRE element upstream of the 3' splice site. This binding functions to repress exon 5a of Snap 25 and competes with the binding of U2AF to the 3' splice site. hnRNP K also controls splicing of genes related to neurological diseases, such as Runx1 [52].

In humans, more than $90 \%$ of transcripts undergo alternative splicing. It is precisely controlled, according to the required tissue and organ function. Mutations in SREs affecting alternative splicing cause human genetic diseases and cancers [53]. Overall, 15\% - 50\% of genetic diseases are caused by aberrant splicing [54]. One example is Alzheimer's disease. HMGA1a, originally described as an oncogene product, has a high affinity for presenilin2 (PS2) pre-mRNA, but its binding results in aberrant splicing that produces mRNA lacking exon 5 (PS2V). PS2V, the protein product of this aberrant splicing, accumulates in the brain of people with Alzheimer's disease, and can cause cell death [55] [56].

In addition to cis- and trans-acting factors, chromatin modification and transcription rate have also been suggested to regulate alternative splicing [53]. The precise regulation of alternative splicing is still not fully unders- 
tood; advances in our understanding will inform on the mechanisms of gene regulation and help to develop therapeutic strategies for human disease.

\subsection{Alternative Polyadenylation}

Alternative polyadenylation (APA) is a phenomenon that produces multiple isoforms of mRNA because of the existence of multiple polyadenylation sites in one gene. APA often controls the fate of mRNA by diversifying the length of the mRNA 3' UTR. A longer 3' UTR is considered to have more cis-elements and therefore have a chance for regulating the mRNA stability (see chapter 3-5 in detail).

Recent genome-wide analyses have revealed that APA is observed widely throughout the genome, and that its pattern varies according to developmental stage and tissue organization [57] [58]. In Drosophila, mRNAs in the central nervous system tend to have longer 3' UTRs, whereas those in the testis have shorter 3' UTRs [59]. An extended 3' UTR is common among transcription factors and RNA-binding proteins, suggesting a relationship with auto- and post-transcriptional regulation. Ongoing studies are attempting to identify consensus sequences for APA and reveal the mechanistic details.

\subsection{Gene Regulation via mRNA Export}

Gene regulation by mRNA export is frequently observed in retroviruses such as human immunodeficiency virus type 1 (HIV-1). HIV-1 possesses a single promoter in its genome and produces just one primary transcript. However, it produces more than 40 multiple mRNA isoforms by alternative splicing. In the early phase, the HIV-1 primary transcript, encoding the Rev protein, is exported into the cytoplasm in a splicing-dependent manner (Figure 4). The Rev protein is translocated into the nucleus, where it is translated in the early phase [60] [61]. The Rev protein binds to the Rev response element (RRE) in the primary transcript [62]. Then, CRM1, an RNA export receptor, recognizes the nuclear export signal in Rev and binds to the primary transcript via Rev proteins [63]. This results in the export of the HIV-1 primary transcript to the cytoplasm via the CRM1-dependent mRNA export pathway. When Rev is bound to the RRE, Rev also interacts with CBP, thus suppressing the recruitment of the TREX components and the TAP-dependent mRNA export pathway [64].

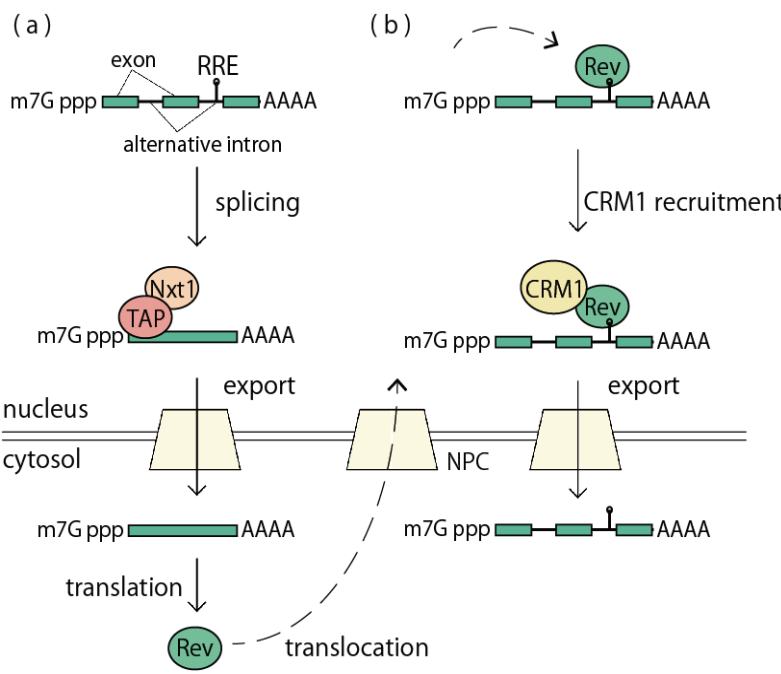

Figure 4. Strategy to export alternatively spliced mRNAs of HIV-1. (a) In the early phase, transcripts of HIV-1 (Figure 4 shows representative isoforms) are exported into the cytoplasm in a splicing-dependent manner. mRNAs exported in this way encode proteins including Rev. Rev is translocated in the nucleus; (b) In the late phase, Rev binds to RRE which is present in an intron of primary transcript of HIV-1. The nuclear export receptor CRM1 is recruited to Rev. As a result, introncontaining mRNAs of HIV-1 are exported to the cytoplasm to propagate. 
TAP controls its expression level by regulating its own mRNA export by a process similar to the "CTE system” in Mason-Pfizer Monkey Virus (MPMV) [65]. MPMV is a retrovirus whose gene expression is regulated by its RNA element, the constitutive transport element (CTE). The CTE is directly recognized and bound by TAP, so mRNA containing a CTE is efficiently exported into the cytoplasm [66], even in an intron-containing form [67]-[70]. Li et al. found that intron 10 of TAP contained an element similar to the CTE found in MPMV and its relatives, which was directly recognized by TAP [65]. When excessive TAP is expressed by chance, saturated TAP directly recognizes and binds the CTE, which results in export of TAP mRNA in an intron-containing form. TAP mRNA in an intron-containing form is likely to be degraded by nonsense-mediated decay, providing a mechanism for auto-regulation.

Recent research has revealed that gene regulation via mRNA export may be more important than previously recognized. GANP is known to promote TAP-dependent mRNA export [71]. Now it has been shown that GANP promotes mRNAs that are highly expressed, short-lived, and highly enriched in central components of the gene expression machineries [72]. It is suggested that GANP enables rapid changes in gene expression by facilitating nuclear export of specific classes of mRNA, by bridging target genes and the nuclear pore.

\subsection{Half-Life of mRNA}

Some genes regulate their expression level by controlling their mRNA half-life. mRNA with a shorter half-life results in lower protein expression level because of reduced translation; this system is frequently found in factors related to the cell cycle, development, and immune responses. Such mRNAs usually have cis-elements in their 3' UTR, including an AU-rich element (ARE) and/or target sites for micro RNAs (miRNAs).

mRNAs containing an ARE tend to be rapidly degraded because the poly-A tail is quickly shortened. AREs are classified into three types according to their sequence, which determines the degradation pathway taken [73] [74]: class I has one to three repeats of “AUUUA"; class II has multiple repeats of "AUUUA", and class III has an A-and-U cluster without any repeats of "AUUUA”. ARE-binding proteins (AUBPs) also determine mRNA fate. There are many AUBPs, such as tristetraprolin (TTP), BRF1, AUF1, the Hu protein family, and ataxin 2. TTP, BRF1, and AUF1 destabilize ARE-containing mRNAs, while the Hu protein family and ataxin 2 stabilize them [75]-[80].

Class II AREs are recognized and bound by TTP. Mice deficient in TTP develop complicated immunological disease soon after birth because stabilization of mRNAs containing class II AREs results in excess expression of $\mathrm{TNF} \alpha$, a major regulator of the immune system, whose mRNA contains a class II ARE [76]. TTP is known to be required for deadenylation, and details of its destabilization mechanism are now emerging. TTP contains a zinc finger $\mathrm{CCCH}$ domain and directly binds to mRNAs via their ARE [81] [82]. However, TTP also binds to the CCR4-NOT multi-functional complex via its subunit, NOT1 [83]. NOT1 recruits the deadenylases Caf1 and CCR4, which results in deadenylation of mRNA containing a class II ARE [84].

miRNAs are small RNAs approximately 22 nt long that regulate gene expression post-transcriptionally via RNA silencing. Most of miRNAs are transcribed as primary miRNA (pri-miRNA) by polII in the nucleus, and has a 5' cap, poly-A tail, and local hairpin structure [85]-[87]. The nuclear RNAse III Drosha and its essential cofactor DGCR8 crop unnecessary stem-loops and single-stranded RNA to form pre-miRNA. After processing, the pre-miRNA is exported to the cytoplasm by exportin 5 with RanGTP, where it is processed by Dicer, and loaded onto Argonaute (AGO) protein to form the RNA-induced silencing complex (RISC). miRNA induces translational repression and/or mRNA degradation by the binding to 3' UTRs. The RISC recognizes the target mRNA by being guided by a mostly complementary miRNA sequence. More than 1000 miRNAs have been identified, implying that the expression of more than 5\% of mRNAs is affected by miRNAs [88]. In fact, microarray data have suggested that almost one third of mRNAs are potential targets for miRNAs, suggesting that this represents a global function rather than a "fine-tuning" mechanism. There appear to be at least two mechanisms for miRNA-mediated gene regulation—initiation-dependent and initiation-independent [87] — but the exact mechanisms are still to be elucidated.

It has also been reported that miRNAs participate in the degradation of ARE-containing mRNAs. Qing et al. showed that components of the RISC such as AGO and miR16 are required for destabilization of ARE-containing mRNA [89]. Interestingly, TTP is also required for this pathway. Because of its apparent importance, uncovering these mechanisms will lead to advances in the understanding of human diseases and developmental processes. 


\section{Conclusion}

Gene regulation is a complex process. The regulation steps include transcription, mRNA processing, mRNA transport and translocation, translation, protein activation and mRNA half-life control. In capping, methylation step is regulated by feedback loop. The meaning of methylation at first and second nucleotide, however, is unclear. In splicing, the selection of each exon is an important step for the different types of protein expression. SR proteins and hnRNPs play important roles for the splice site selection. In APA, selection of APA site determines the mRNA half-life. Specific sequence located mostly at 3' UTR is the target site for AUBPs as well as miRNAs and regulates the stability of mRNA. Output of multiple gene regulations results in specific expression pattern and determines the cell specific phenotype.

\section{Acknowledgements}

This work was supported by grants-in-aid from the Ministry of Education, Culture, Sports, Science and Technology of Japan, the Skylark Food Science Institute, The TojuroIijima Foundation for Food Science and Technology, The Foundation for Dietary Scientific Research, the Noda Institute for Scientific Research and Technology, and The Fuji Foundation for Protein Research to S. M.

\section{References}

[1] Hirose, Y. and Manley, J.L. (2000) RNA Polymerase II and the Integration of Nuclear Events. Genes \& Development, 14, 1415-1429.

[2] Staley, J.P. and Guthrie, C. (1998) Mechanical Devices of the Spliceosome: Motors, Clocks, Springs, and Things. Cell, 92, 315-326. http://dx.doi.org/10.1016/S0092-8674(00)80925-3

[3] Matera, A.G. and Wang, Z. (2014) A Day in the Life of the Spliceosome. Nature Reviews Molecular Cell Biology, 15, 108-121. http://dx.doi.org/10.1038/nrm3742

[4] Colgan, D.F. and Manley, J.L. (1997) Mechanism and Regulation of mRNA Polyadenylation. Genes \& Development, 11, 2755-2766. http://dx.doi.org/10.1101/gad.11.21.2755

[5] Mangus, D.A., Evans, M.C. and Jacobson, A. (2003) Poly(A)-Binding Proteins: Multifunctional Scaffolds for the PostTranscriptional Control of Gene Expression. Genome Biology, 4, 223. http://dx.doi.org/10.1186/gb-2003-4-7-223

[6] Culjkovic-Kraljacic, B. and Borden, K.L. (2013) Aiding and Abetting Cancer: mRNA Export and the Nuclear Pore. Trends in Cell Biology, 23, 328-335. http://dx.doi.org/10.1016/j.tcb.2013.03.004

[7] Natalizio, B.J. and Wente, S.R. (2013) Postage for the Messenger: Designating Routes for Nuclear mRNA Export. Trends in Cell Biology, 23, 365-373. http://dx.doi.org/10.1016/j.tcb.2013.03.006

[8] Strasser, K., Masuda, S., Mason, P., Pfannstiel, J., Oppizzi, M., Rodriguez-Navarro, S., Rondon, A.G., Aguilera, A., Struhl, K., Reed, R. and Hurt, E. (2002) TREX Is a Conserved Complex Coupling Transcription with Messenger RNA Export. Nature, 417, 304-308. http://dx.doi.org/10.1038/nature746

[9] Gwizdek, C., Iglesias, N., Rodriguez, M.S., Ossareh-Nazari, B., Hobeika, M., Divita, G., Stutz, F. and Dargemont, C. (2006) Ubiquitin-Associated Domain of Mex67 Synchronizes Recruitment of the mRNA Export Machinery with Transcription. Proceedings of the National Academy of Sciences of the United States of America, 103, 16376-16381. http://dx.doi.org/10.1073/pnas.0607941103

[10] Zhou, Z., Luo, M.J., Straesser, K., Katahira, J., Hurt, E. and Reed, R. (2000) The Protein Aly Links Pre-Messenger-RNA Splicing to Nuclear Export in Metazoans. Nature, 407, 401-405. http://dx.doi.org/10.1038/35030160

[11] Zhou, Z., Licklider, L.J., Gygi, S.P. and Reed, R. (2002) Comprehensive Proteomic Analysis of the Human Spliceosome. Nature, 419, 182-185.

[12] Masuda, S., Das, R., Cheng, H., Hurt, E., Dorman, N. and Reed, R. (2005) Recruitment of the Human TREX Complex to mRNA during Splicing. Genes \& Development, 19, 1512-1517. http://dx.doi.org/10.1101/gad.1302205

[13] Yamazaki, T., Fujiwara, N., Yukinaga, H., Ebisuya, M., Shiki, T., Kurihara, T., Kioka, N., Kambe, T., Nagao, M., Nishida, E. and Masuda, S. (2010) The Closely Related RNA Helicases, UAP56 and URH49, Preferentially form Distinct mRNA Export Machineries and Coordinately Regulate Mitotic Progression. Molecular Biology of the Cell, 21, 29532965. http://dx.doi.org/10.1091/mbc.E09-10-0913

[14] Rout, M.P., Aitchison, J.D., Suprapto, A., Hjertaas, K., Zhao, Y. and Chait, B.T. (2000) The Yeast Nuclear Pore Complex: Composition, Architecture, and Transport Mechanism. Journal of Cell Biology, 148, 635-651. http://dx.doi.org/10.1083/jcb.148.4.635

[15] Fribourg, S., Braun, I.C., Izaurralde, E. and Conti, E. (2001) Structural Basis for the Recognition of a Nucleoporin FG 
Repeat by the NTF2-Like Domain of the TAP/p15 mRNA Nuclear Export Factor. Molecular Cell, 8, 645-656. http://dx.doi.org/10.1016/S1097-2765(01)00348-3

[16] Ribbeck, K. and Gorlich, D. (2001) Kinetic Analysis of Translocation through Nuclear Pore Complexes. The EMBO Journal, 20, 1320-1330. http://dx.doi.org/10.1093/emboj/20.6.1320

[17] Grant, R.P., Hurt, E., Neuhaus, D. and Stewart, M. (2002) Structure of the C-Terminal FG-Nucleoporin Binding Domain of Tap/NXF1. Nature Structural Biology, 9, 247-251. http://dx.doi.org/10.1038/nsb773

[18] Alcazar-Roman, A.R., Tran, E.J., Guo, S. and Wente, S.R. (2006) Inositol Hexakisphosphate and Gle1 Activate the DEAD-Box Protein Dbp5 for Nuclear mRNA Export. Nature Cell Biology, 8, 711-716. http://dx.doi.org/10.1038/ncb1427

[19] Weirich, C.S., Erzberger, J.P., Flick, J.S., Berger, J.M., Thorner, J. and Weis, K. (2006) Activation of the DExD/ $\mathrm{H}-$ Box Protein Dbp5 by the Nuclear-Pore Protein Gle1 and Its Coactivator InsP ${ }_{6}$ Is Required for mRNA Export. Nature Cell Biology, 8, 668-676. http://dx.doi.org/10.1038/ncb1424

[20] Tran, E.J., Zhou, Y., Corbett, A.H. and Wente, S.R. (2007) The DEAD-Box Protein Dbp5 Controls mRNA Export by Triggering Specific RNA:Protein Remodeling Events. Molecular Cell, 28, 850-859. http://dx.doi.org/10.1016/j.molcel.2007.09.019

[21] Hutten, S. and Kehlenbach, R.H. (2007) CRM1-Mediated Nuclear Export: To the Pore and Beyond. Trends in Cell Biology, 17, 193-201. http://dx.doi.org/10.1016/j.tcb.2007.02.003

[22] Fornerod, M., Ohno, M., Yoshida, M. and Mattaj, I.W. (1997) CRM1 Is an Export Receptor for Leucine-Rich Nuclear Export Signals. Cell, 90, 1051-1060. http://dx.doi.org/10.1016/S0092-8674(00)80371-2

[23] Kehlenbach, R.H., Dickmanns, A., Kehlenbach, A., Guan, T. and Gerace, L. (1999) A Role for RanBP1 in the Release of CRM1 from the Nuclear Pore Complex in a Terminal Step of Nuclear Export. Journal of Cell Biology, 145, 645-657. http://dx.doi.org/10.1083/jcb.145.4.645

[24] Bischoff, F.R. and Ponstingl, H. (1991) Catalysis of Guanine Nucleotide Exchange on Ran by the Mitotic Regulator RCC1. Nature, 354, 80-82.

[25] Schwer, B., Saha, N., Mao, X., Chen, H.W. and Shuman, S. (2000) Structure-Function Analysis of Yeast mRNA Cap Methyltransferase and High-Copy Suppression of Conditional Mutants by AdoMet Synthase and the Ubiquitin Conjugating Enzyme Cdc34p. Genetics, 155, 1561-1576.

[26] Chiang, P.K., Gordon, R.K., Tal, J., Zeng, G.C., Doctor, B.P., Pardhasaradhi, K. and McCann, P.P. (1996) S-Adenosylmethionine and Methylation. The FASEB Journal, 10, 471-480.

[27] Gorlich, D., Kraft, R., Kostka, S., Vogel, F., Hartmann, E., Laskey, R.A., Mattaj, I.W. and Izaurralde, E. (1996) Importin Provides a Link between Nuclear Protein Import and U snRNA Export. Cell, 87, 21-32. http://dx.doi.org/10.1016/S0092-8674(00)81319-7

[28] Wen, Y. and Shatkin, A.J. (2000) Cap Methyltransferase Selective Binding and Methylation of GpppG-RNA Are Stimulated by Importin- $\alpha$. Genes \& Development, 14, 2944-2949. http://dx.doi.org/10.1101/gad.848200

[29] Dias, S.M., Wilson, K.F., Rojas, K.S., Ambrosio, A.L. and Cerione, R.A. (2009) The Molecular Basis for the Regulation of the Cap-Binding Complex by the Importins. Nature Structural \& Molecular Biology, 16, 930-937. http://dx.doi.org/10.1038/nsmb.1649

[30] Furuichi, Y., Morgan, M., Shatkin, A.J., Jelinek, W., Salditt-Georgieff, M. and Darnell, J.E. (1975) Methylated, Blocked 5 Termini in HeLa Cell mRNA. Proceedings of the National Academy of Sciences of the United States of America, 72, 1904-1908. http://dx.doi.org/10.1073/pnas.72.5.1904

[31] Zamudio, J.R., Mittra, B., Campbell, D.A. and Sturm, N.R. (2009) Hypermethylated Cap 4 Maximizes Trypanosoma Brucei Translation. Molecular Microbiology, 72, 1100-1110. http://dx.doi.org/10.1111/j.1365-2958.2009.06696.x

[32] Belanger, F., Stepinski, J., Darzynkiewicz, E. and Pelletier, J. (2010) Characterization of hMTr1, a Human Cap1 2'-O-Ribose Methyltransferase. The Journal of Biological Chemistry, 285, 33037-33044. http://dx.doi.org/10.1074/jbc.M110.155283

[33] Werner, M., Purta, E., Kaminska, K.H., Cymerman, I.A., Campbell, D.A., Mittra, B., Zamudio, J.R., Sturm, N.R., Jaworski, J. and Bujnicki, J.M. (2011) 2'-O-Ribose Methylation of Cap2 in Human: Function and Evolution in a Horizontally Mobile Family. Nucleic Acids Research, 39, 4756-4768. http://dx.doi.org/10.1093/nar/gkr038

[34] Smietanski, M., Werner, M., Purta, E., Kaminska, K.H., Stepinski, J., Darzynkiewicz, E., Nowotny, M. and Bujnicki, J.M. (2014) Structural Analysis of Human 2'-O-Ribose Methyltransferases Involved in mRNA Cap Structure Formation. Nature Communications, 5, Article Number: 3004.

[35] Van Dijk, E., Cougot, N., Meyer, S., Babajko, S., Wahle, E. and Seraphin, B. (2002) Human Dcp2: A Catalytically Active mRNA Decapping Enzyme Located in Specific Cytoplasmic Structures. The EMBO Journal, 21, 6915-6924. http://dx.doi.org/10.1093/emboj/cdf678 
[36] Piccirillo, C., Khanna, R. and Kiledjian, M. (2003) Functional Characterization of the Mammalian mRNA Decapping Enzyme hDcp2. RNA, 9, 1138-1147.

[37] Jiao, X., Xiang, S., Oh, C., Martin, C.E., Tong, L. and Kiledjian, M. (2010) Identification of a Quality-Control Mechanism for mRNA 5'-End Capping. Nature, 467, 608-611. http://dx.doi.org/10.1038/nature09338

[38] Cartegni, L., Chew, S.L. and Krainer, A.R. (2002) Listening to Silence and Understanding Nonsense: Exonic Mutations that Affect Splicing. Nature Reviews Genetics, 3, 285-298. http://dx.doi.org/10.1038/nrg775

[39] Fu, X.D. and Ares Jr., M. (2014) Context-Dependent Control of Alternative Splicing by RNA-Binding Proteins. Nature Reviews Genetics, 15, 689-701. http://dx.doi.org/10.1038/nrg3778

[40] Wang, Z. and Burge, C.B. (2008) Splicing Regulation: From a Parts List of Regulatory Elements to an Integrated Splicing Code. RNA, 14, 802-813. http://dx.doi.org/10.1261/rna.876308

[41] Warf, M.B. and Berglund, J.A. (2010) Role of RNA Structure in Regulating Pre-mRNA Splicing. Trends in Biochemical Sciences, 35, 169-178. http://dx.doi.org/10.1016/j.tibs.2009.10.004

[42] Wang, Y., Xiao, X., Zhang, J., Choudhury, R., Robertson, A., Li, K., Ma, M., Burge, C.B. and Wang, Z. (2013) A Complex Network of Factors with Overlapping Affinities Represses Splicing through Intronic Elements. Nature Structural \& Molecular Biology, 20, 36-45. http://dx.doi.org/10.1038/nsmb.2459

[43] Erkelenz, S., Mueller, W.F., Evans, M.S., Busch, A., Schoneweis, K., Hertel, K.J. and Schaal, H. (2013) Position-Dependent Splicing Activation and Repression by SR and hnRNP Proteins Rely on Common Mechanisms. RNA, 19, 96102. http://dx.doi.org/10.1261/rna.037044.112

[44] Wang, Y., Ma, M., Xiao, X. and Wang, Z. (2012) Intronic Splicing Enhancers, Cognate Splicing Factors and Context-Dependent Regulation Rules. Nature Structural \& Molecular Biology, 19, 1044-1052. http://dx.doi.org/10.1038/nsmb.2377

[45] Ghigna, C., Giordano, S., Shen, H., Benvenuto, F., Castiglioni, F., Comoglio, P.M., Green, M.R., Riva, S. and Biamonti, G. (2005) Cell Motility Is Controlled by SF2/ASF through Alternative Splicing of the Ron Protooncogene. Molecular Cell, 20, 881-890. http://dx.doi.org/10.1016/j.molcel.2005.10.026

[46] Anczukow, O., Rosenberg, A.Z., Akerman, M., Das, S., Zhan, L., Karni, R., Muthuswamy, S.K. and Krainer, A.R. (2012) The Splicing Factor SRSF1 Regulates Apoptosis and Proliferation to Promote Mammary Epithelial Cell Transformation. Nature Structural \& Molecular Biology, 19, 220-228. http://dx.doi.org/10.1038/nsmb.2207

[47] O’Connor, L., Strasser, A., O'Reilly, L.A., Hausmann, G., Adams, J.M., Cory, S. and Huang, D.C. (1998) Bim: A Novel Member of the Bcl-2 Family That Promotes Apoptosis. The EMBO Journal, 17, 384-395. http://dx.doi.org/10.1093/emboj/17.2.384

[48] Hui, J., Stangl, K., Lane, W.S. and Bindereif, A. (2003) HnRNP L Stimulates Splicing of the eNOS Gene by Binding to Variable-Length CA Repeats. Nature Structural \& Molecular Biology, 10, 33-37. http://dx.doi.org/10.1038/nsb875

[49] Heiner, M., Hui, J., Schreiner, S., Hung, L.H. and Bindereif, A. (2010) HnRNP L-Mediated Regulation of Mammalian Alternative Splicing by Interference with Splice Site Recognition. RNA Biology, 7, 56-64. http://dx.doi.org/10.4161/rna.7.1.10402

[50] Hung, L.H., Heiner, M., Hui, J., Schreiner, S., Benes, V. and Bindereif, A. (2008) Diverse Roles of hnRNP L in Mammalian mRNA Processing: A Combined Microarray and RNAi Analysis. RNA, 14, 284-296. http://dx.doi.org/10.1261/rna.725208

[51] Rossbach, O., Hung, L.H., Khrameeva, E., Schreiner, S., Konig, J., Curk, T., Zupan, B., Ule, J., Gelfand, M.S. and Bindereif, A. (2014) Crosslinking-Immunoprecipitation (iCLIP) Analysis Reveals Global Regulatory Roles of hnRNP L. RNA Biology, 11, 146-155. http://dx.doi.org/10.4161/rna.27991

[52] Cao, W., Razanau, A., Feng, D., Lobo, V.G. and Xie, J. (2012) Control of Alternative Splicing by Forskolin through hnRNP K during Neuronal Differentiation. Nucleic Acids Research, 40, 8059-8071. http://dx.doi.org/10.1093/nar/gks504

[53] Kornblihtt, A.R., Schor, I.E., Allo, M., Dujardin, G., Petrillo, E. and Munoz, M.J. (2013) Alternative splicing: A Pivotal Step between Eukaryotic Transcription and Translation. Nature Reviews Molecular Cell Biology, 14, 153-165. http://dx.doi.org/10.1038/nrm3525

[54] Caceres, J.F. and Kornblihtt, A.R. (2002) Alternative Splicing: Multiple Control Mechanisms and Involvement in Human Disease. Trends in Genetics, 18, 186-193. http://dx.doi.org/10.1016/S0168-9525(01)02626-9

[55] Manabe, T., Ohe, K., Katayama, T., Matsuzaki, S., Yanagita, T., Okuda, H., Bando, Y., Imaizumi, K., Reeves, R., Tohyama, M. and Mayeda, A. (2007) HMGA1a: Sequence-Specific RNA-Binding Factor Causing Sporadic Alzheimer's Disease-Linked Exon Skipping of Presenilin-2 Pre-mRNA. Genes to Cells, 12, 1179-1191. http://dx.doi.org/10.1111/j.1365-2443.2007.01123.x

[56] Manabe, T., Katayama, T., Sato, N., Gomi, F., Hitomi, J., Yanagita, T., Kudo, T., Honda, A., Mori, Y., Matsuzaki, S., 
Imaizumi, K., Mayeda, A. and Tohyama, M. (2003) Induced HMGA1a Expression Causes Aberrant Splicing of Presenilin-2 Pre-mRNA in Sporadic Alzheimer's Disease. Cell Death and Differentiation, 10, 698-708. http://dx.doi.org/10.1038/sj.cdd.4401221

[57] Ji, Z., Lee, J.Y., Pan, Z., Jiang, B. and Tian, B. (2009) Progressive Lengthening of 3' Untranslated Regions of mRNAs by Alternative Polyadenylation during Mouse Embryonic Development. Proceedings of the National Academy of Sciences of the United States of America, 106, 7028-7033. http://dx.doi.org/10.1073/pnas.0900028106

[58] Ji, Z. and Tian, B. (2009) Reprogramming of 3' Untranslated Regions of mRNAs by Alternative Polyadenylation in Generation of Pluripotent Stem Cells from Different Cell Types. PLoS ONE, 4, e8419. http://dx.doi.org/10.1371/journal.pone.0008419

[59] Smibert, P., Miura, P., Westholm, J.O., Shenker, S., May, G., Duff, M.O., Zhang, D., Eads, B.D., Carlson, J., Brown, J.B., Eisman, R.C., Andrews, J., Kaufman, T., Cherbas, P., Celniker, S.E., Graveley, B.R. and Lai, E.C. (2012) Global Patterns of Tissue-Specific Alternative Polyadenylation in Drosophila. Cell Reports, 1, 277-289.

[60] Meyer, B.E. and Malim, M.H. (1994) The HIV-1 Rev Trans-Activator Shuttles between the Nucleus and the Cytoplasm. Genes \& Development, 8, 1538-1547. http://dx.doi.org/10.1101/gad.8.13.1538

[61] Richard, N., Iacampo, S. and Cochrane, A. (1994) HIV-1 Rev Is Capable of Shuttling between the Nucleus and Cytoplasm. Virology, 204, 123-131. http://dx.doi.org/10.1006/viro.1994.1516

[62] Heaphy, S., Dingwall, C., Ernberg, I., Gait, M.J., Green, S.M., Karn, J., Lowe, A.D., Singh, M. and Skinner, M.A. (1990) HIV-1 Regulator of Virion Expression (Rev) Protein Binds to an RNA Stem-Loop Structure Located within the Rev Response Element Region. Cell, 60, 685-693. http://dx.doi.org/10.1016/0092-8674(90)90671-Z

[63] Askjaer, P., Jensen, T.H., Nilsson, J., Englmeier, L. and Kjems, J. (1998) The Specificity of the CRM1-Rev Nuclear Export Signal Interaction Is Mediated by RanGTP. The Journal of Biological Chemistry, 273, 33414-33422. http://dx.doi.org/10.1074/jbc.273.50.33414

[64] Taniguchi, I., Mabuchi, N. and Ohno, M. (2014) HIV-1 Rev Protein Specifies the Viral RNA Export Pathway by Suppressing TAP/NXF1 Recruitment. Nucleic Acids Research, 42, 6645-6658. http://dx.doi.org/10.1093/nar/gku304

[65] Li, Y., Bor, Y.C., Misawa, Y., Xue, Y., Rekosh, D. and Hammarskjold, M.L. (2006) An Intron with a Constitutive Transport Element Is Retained in a Tap Messenger RNA. Nature, 443, 234-237.

[66] Aihara, Y., Fujiwara, N., Yamazaki, T., Kambe, T., Nagao, M., Hirose, Y. and Masuda, S. (2011) Enhancing Recombinant Protein Production in Human Cell Lines with a Constitutive Transport Element and mRNA Export Proteins. Journal of Biotechnology, 153, 86-91. http://dx.doi.org/10.1016/j.jbiotec.2011.03.024

[67] Gruter, P., Tabernero, C., von Kobbe, C., Schmitt, C., Saavedra, C., Bachi, A., Wilm, M., Felber, B.K. and Izaurralde, E. (1998) TAP, the Human Homolog of Mex67p, Mediates CTE-Dependent RNA Export from the Nucleus. Molecular Cell, 1, 649-659. http://dx.doi.org/10.1016/S1097-2765(00)80065-9

[68] Liker, E., Fernandez, E., Izaurralde, E. and Conti, E. (2000) The Structure of the mRNA Export Factor TAP Reveals a cis Arrangement of a Non-Canonical RNP Domain and an LRR Domain. The EMBO Journal, 19, 5587-5598. http://dx.doi.org/10.1093/emboj/19.21.5587

[69] Tabernero, C., Zolotukhin, A.S., Valentin, A., Pavlakis, G.N. and Felber, B.K. (1996) The Posttranscriptional Control Element of the Simian Retrovirus Type 1 Forms an Extensive RNA Secondary Structure Necessary for Its Function. Journal of Virology, 70, 5998-6011.

[70] Ernst, R.K., Bray, M., Rekosh, D. and Hammarskjold, M.L. (1997) A Structured Retroviral RNA Element That Mediates Nucleocytoplasmic Export of Intron-Containing RNA. Molecular and Cellular Biology, 17, 135-144.

[71] Wickramasinghe, V.O., McMurtrie, P.I., Mills, A.D., Takei, Y., Penrhyn-Lowe, S., Amagase, Y., Main, S., Marr, J., Stewart, M. and Laskey, R.A. (2010) mRNA Export from Mammalian Cell Nuclei Is Dependent on GANP. Current Biology, 20, 25-31. http://dx.doi.org/10.1016/j.cub.2009.10.078

[72] Wickramasinghe, V.O., Andrews, R., Ellis, P., Langford, C., Gurdon, J.B., Stewart, M., Venkitaraman, A.R. and Laskey, R.A. (2014) Selective Nuclear Export of Specific Classes of mRNA from Mammalian Nuclei Is Promoted by GANP. Nucleic Acids Research, 42, 5059-5071. http://dx.doi.org/10.1093/nar/gku095

[73] Xu, N., Chen, C.Y. and Shyu, A.B. (1997) Modulation of the Fate of Cytoplasmic mRNA by AU-Rich Elements: Key Sequence Features Controlling mRNA Deadenylation and Decay. Molecular and Cellular Biology, 17, 4611-4621.

[74] Bakheet, T., Frevel, M., Williams, B.R., Greer, W. and Khabar, K.S. (2001) ARED: Human AU-Rich Element-Containing mRNA Database Reveals an Unexpectedly Diverse Functional Repertoire of Encoded Proteins. Nucleic Acids Research, 29, 246-254. http://dx.doi.org/10.1093/nar/29.1.246

[75] Zhang, W., Wagner, B.J., Ehrenman, K., Schaefer, A.W., DeMaria, C.T., Crater, D., DeHaven, K., Long, L. and Brewer, G. (1993) Purification, Characterization, and cDNA Cloning of an AU-Rich Element RNA-Binding Protein, AUF1. Molecular and Cellular Biology, 13, 7652-7665. 
[76] Carballo, E., Lai, W.S. and Blackshear, P.J. (1998) Feedback Inhibition of Macrophage Tumor Necrosis Factor- $\alpha$ Production by Tristetraprolin. Science, 281, 1001-1005. http://dx.doi.org/10.1126/science.281.5379.1001

[77] Antic, D., Lu, N. and Keene, J.D. (1999) ELAV Tumor Antigen, Hel-N1, Increases Translation of Neurofilament M mRNA and Induces Formation of Neurites in Human Teratocarcinoma Cells. Genes \& Development, 13, 449-461. http://dx.doi.org/10.1101/gad.13.4.449

[78] Keene, J.D. (1999) Why Is Hu Where? Shuttling of Early-Response-Gene Messenger RNA Subsets. Proceedings of the National Academy of Sciences of the United States of America, 96, 5-7. http://dx.doi.org/10.1073/pnas.96.1.5

[79] Stoecklin, G., Colombi, M., Raineri, I., Leuenberger, S., Mallaun, M., Schmidlin, M., Gross, B., Lu, M., Kitamura, T. and Moroni, C. (2002) Functional Cloning of BRF1, a Regulator of ARE-Dependent mRNA Turnover. The EMBO Journal, 21, 4709-4718. http://dx.doi.org/10.1093/emboj/cdf444

[80] Yokoshi, M., Li, Q., Yamamoto, M., Okada, H., Suzuki, Y. and Kawahara, Y. (2014) Direct Binding of Ataxin-2 to Distinct Elements in 3' UTRs Promotes mRNA Stability and Protein Expression. Molecular Cell, 55, 186-198. http://dx.doi.org/10.1016/j.molcel.2014.05.022

[81] Lai, W.S., Carballo, E., Strum, J.R., Kennington, E.A., Phillips, R.S. and Blackshear, P.J. (1999) Evidence that Tristetraprolin Binds to AU-Rich Elements and Promotes the Deadenylation and Destabilization of Tumor Necrosis Factor alpha mRNA. Journal of Molecular Cell Biology, 19, 4311-4323.

[82] Hudson, B.P., Martinez-Yamout, M.A., Dyson, H.J. and Wright, P.E. (2004) Recognition of the mRNA AU-Rich Element by the Zinc Finger Domain of TIS11d. Nature Structural \& Molecular Biology, 11, 257-264.

[83] Fabian, M.R., Frank, F., Rouya, C., Siddiqui, N., Lai, W.S., Karetnikov, A., Blackshear, P.J., Nagar, B. and Sonenberg, N. (2013) Structural Basis for the Recruitment of the Human CCR4-NOT Deadenylase Complex by Tristetraprolin. Nature Structural \& Molecular Biology, 20, 735-739. http://dx.doi.org/10.1038/nsmb.2572

[84] Sandler, H., Kreth, J., Timmers, H.T. and Stoecklin, G. (2011) Not1 Mediates Recruitment of the Deadenylase Caf1 to mRNAs Targeted for Degradation by Tristetraprolin. Nucleic Acids Research, 39, 4373-4386. http://dx.doi.org/10.1093/nar/gkr011

[85] Liu, J. (2008) Control of Protein Synthesis and mRNA Degradation by microRNAs. Current Opinion in Cell Biology, 20, 214-221. http://dx.doi.org/10.1016/j.ceb.2008.01.006

[86] Cannell, I.G., Kong, Y.W. and Bushell, M. (2008) How do microRNAs Regulate Gene Expression? Biochemical Society Transactions, 36, 1224-1231. http://dx.doi.org/10.1042/BST0361224

[87] Ha, M. and Kim, V.N. (2014) Regulation of microRNA Biogenesis. Nature Reviews Molecular Cell Biology, 15, 509524. http://dx.doi.org/10.1038/nrm3838

[88] Brummer, A. and Hausser, J. (2014) MicroRNA Binding Sites in the Coding Region of mRNAs: Extending the Repertoire of Post-Transcriptional Gene Regulation. BioEssays, 36, 617-626. http://dx.doi.org/10.1002/bies.201300104

[89] Jing, Q., Huang, S., Guth, S., Zarubin, T., Motoyama, A., Chen, J., Di Padova, F., Lin, S.C., Gram, H. and Han, J. (2005) Involvement of microRNA in AU-Rich Element-Mediated mRNA Instability. Cell, 120, 623-634. http://dx.doi.org/10.1016/j.cell.2004.12.038 